WSRC-TR-2003-00490

Revision 0

\author{
ELECTRIC DISCHARGE MACHINING TECHNIQUES FOR \\ EVALUATING THE EFFECTS OF TRITIUM ON MATERIALS (U) \\ MICHAEL J. MORGAN \\ AND \\ KENNETH J. IMRICH
}

SAVANNAH RIVER TECHNOLOGY CENTER

Publication Date: February 4, 2004

Westinghouse Savannah River Company

Savannah River Site

Aiken, SC 29808

PREPARED FOR THE U.S. DEPARTMENT OF ENERGY UNDER CONTRACT DE-AC09-96SR18500 
This document was prepared in conjunction with work accomplished under Contract No. DE-AC09-96SR18500 with the U. S. Department of Energy.

\section{DISCLAIMER}

This report was prepared as an account of work sponsored by an agency of the United States Government. Neither the United States Government nor any agency thereof, nor any of their employees, makes any warranty, express or implied, or assumes any legal liability or responsibility for the accuracy, completeness, or usefulness of any information, apparatus, product or process disclosed, or represents that its use would not infringe privately owned rights. Reference herein to any specific commercial product, process or service by trade name, trademark, manufacturer, or otherwise does not necessarily constitute or imply its endorsement, recommendation, or favoring by the United States Government or any agency thereof. The views and opinions of authors expressed herein do not necessarily state or reflect those of the United States Government or any agency thereof.

This report has been reproduced directly from the best available copy.

Available for sale to the public, in paper, from: U.S. Department of Commerce, National Technical Information Service, 5285 Port Royal Road, Springfield, VA 22161, phone: (800) 553-6847, fax: (703) 605-6900

email: orders@ntis.fedworld.gov

online ordering: http://www.ntis.gov/help/index.asp

Available electronically at http://www.osti.gov/bridge

Available for a processing fee to U.S. Department of Energy and its contractors, in paper, from: U.S. Department of Energy, Office of Scientific and Technical Information, P.O. Box 62, Oak Ridge, TN 37831-0062,

phone: (865)576-8401,

fax: (865)576-5728

email: $\underline{\text { reports@ adonis.osti.gov }}$ 
Keywords:

Stainless Steel

Fracture Toughness

Mechanical Properties

Reservoir

Retention: 25 Years

\title{
Electric Discharge Machining Techniques for Evaluating the Effects of Tritium on Materials (U)
}

\author{
Michael J. Morgan \\ and
}

Kenneth J. Imrich,

Issued:

February 4, 2004 


\section{TABLE OF CONTENTS}

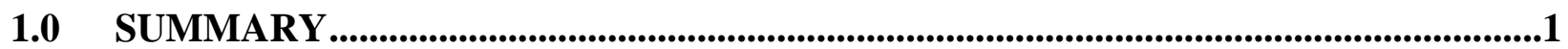

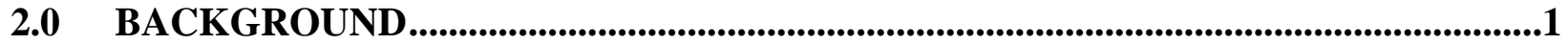

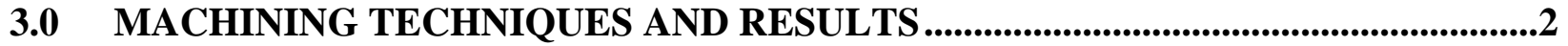

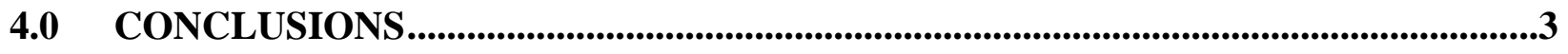

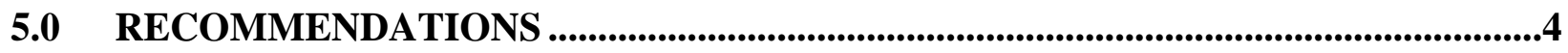

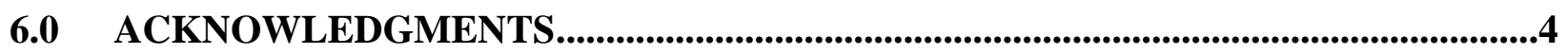




\section{LIST OF FIGURES}

Figure 1 Hansvedt DS-2 PartMaker wire EDM..................................................................

Figure 2 Photographs showing the wire EDM cuts necessary to section tensile specimens from 0.5 inch, sch. 10 pipe. ..................................................................................

Figure 3 Rectangular tensile specimens cut from mid wall of the $1 / 2$ inch schedule 10 pipe and nominal dimensions......................................................................................

Figure 4 Typical stress strain data obtained from longitudinal EDM miniature tensile sample for T-Type reservoir..................................................................................6

Figure 5 Stress strain diagrams for full-size and miniature tensile specimens........................6

Figure 6 Large diameter mock-up reservoir showing locations where longitudinal and transverse tensile test coupons were sectioned from ID wall......................................7

Figure 7 A small diameter mock-up reservoir showing locations where longitudinal and transverse tensile test coupons were sectioned from ID wall......................................

Figure 8 Boss from Type K reservoir mock-up after initial wire EDM process. .....................8

Figure 9 Drawing of the $\mathrm{C}$ sample including notch and side grooves.....................................8 


\section{Electric Discharge Machining Techniques for Evaluating the Effects of Tritium on Materials (U)}

\subsection{SUMMARY}

In this investigation, new ways to evaluate the long-term effects of tritium on the structural properties of components were developed. Electric discharge machining (EDM) techniques for cutting tensile and fracture toughness samples from the tritium-exposed regions of returned reservoirs were demonstrated. An existing electric discharge machine in the 773-A Materials Laboratory was used to cut sub-size tensile and fracture toughness samples from the inside walls of reservoir mock-ups. Tensile properties from the EDM tensile samples were similar to those measured using full-size samples cut from similar stock. Although the existing equipment could not be used for machining tritium-exposed hardware, off-the-shelf EDM units are available that could. With the right equipment and the required radiological controls in place, similar machining and testing techniques could be used to directly measure the effects of tritium on the properties of material cut from reservoir returns. Stress-strain property data from tritiumexposed reservoirs would improve finite-element modeling of reservoir performance because the data are representative of the true state of the reservoir material in the field. Tensile data from samples cut directly from reservoirs will complement existing shelf storage and burst test data of the Life Storage Program and help answer questions about a specific reservoir's processing history and properties. This work was performed under Enhanced Surveillance Campaign Task TSR12, "Enhanced Surveillance of Advanced Design Reservoirs.”

\subsection{BACKGROUND}

Tritium and its decay product, helium, change the structural properties of stainless steels. Tritium exposed steels generally exhibit higher yield strength, lower elongation and ductility, lower fracture toughness, and increased susceptibility to crack growth under sustained loads. The degree of property change depends on the tritium exposure history because it results from the dissolution and diffusion of tritium into the steel and its radioactive decay to helium. Most of the quantitative data that is used to characterize the effects of tritium has been collected from longterm storage and burst tests of accelerated aged reservoirs. Indirect measurements using tensile and fracture toughness tests on samples exposed to tritium prior to testing have also been used. Invariably, questions arise as to the exact condition of a reservoir because its tritium exposure history and material processing history is different from those used in simulated tests.

Today, modern numerical computational techniques like those used in the Enhanced Surveillance Campaign are available to better predict reservoir aging and performance. However, these tools require accurate material property data. Until now, direct measurements of the effects of tritium on the properties of reservoir material seemed exceedingly difficult because the affected material is in the near-surface regions of the reservoir walls. The material properties in that region are highly dependent on reservoir geometry and the steep concentration gradients of tritium and helium. Techniques are needed to directly measure the effects of tritium on the properties of returned reservoirs for complete structural integrity assessments. 


\subsection{MACHINING TECHNIQUES AND RESULTS}

Electric discharge machining was chosen as the preferred machining technique because tensile samples could not be fabricated using existing cutting or machining capabilities. EDM has an advantage in that it is one machining method that can be programmed to fabricate sub-sized test samples from specific areas of small components. It utilizes electrical discharges to cut material from the work piece and is capable of cutting any conductive material including, carbide, high alloy steels, and hardened materials. It can accurately cut very thin sheet and large stock 12 or more inches thick depending on the particular machine. Figure 1 shows a picture of the Hansvedt DS-2 PartMaker wire EDM used in this study. The machine is in the Materials Laboratory of Building 773A and was used on clean reservoir mock-ups to demonstrate the feasibility of the cutting techniques and to investigate the effects of electric-discharge machining on the mechanical property data.

To machine a sample, the work piece is secured to a CNC, X, Y table that moves in a programmed path around the 0.014 in diameter vertically aligned wire electrode. The servo system precisely maintains a fixed distance or gap between the work piece and the wire. Electrical discharges from the charged wire erodes a slot by vaporization, melting and an explosive effect in the material as the table and work piece are advanced around the wire. Although the material removed by an individual discharge is small, the discharge rate can be in excess of 300,000 per second resulting in significant material removal. Deionized water, which is flushed through the slot to insulate the gap, is also used to solidify and wash away the eroded particles. The large volume of water used also serves to minimize heat input into the bulk material.

The one draw back of this technology is that it produces a recast layer, up to 3 mils thick, on the cut surface of the component. Depending on the size of the test sample this layer may affect the desired property data. There are several EDM process parameters that can be adjusted to minimize recast layer thickness, modify material removal rates, increase dimensional accuracy, and minimize surface roughness. These include peak current, servo speed, on/off (or percent ontime) and arc duration. In addition, the technology has advanced so that trim passes as small as 0.0002 inches can be made to further decrease the recast layer.

In preparation for cutting mock-up reservoirs, miniature longitudinal tensile specimens, 0.020 in thick, were sectioned from the inner and outer wall of a 0.5 in Schedule 10 Type 304L stainless steel pipe (wall thickness 0.083 in). Pipe was chosen because it roughly resembled several of the mock-up reservoirs and because multiple tests were required to develop the technique, including fixturing and EDM process parameters. Cutting the tensile specimens took two steps and required the fabrication of a V-block holder to accurately position the pipe on the EDM table.

The first step was to remove a 1.25 in long, 0.020 in thick, semicircular section from the inner and outer diameters of the pipe. The semicircular sections were then Gas Tungsten Arc (GTA) welded to a rod and the longitudinal tensile specimens were cut (Figure 2b). Curved transverse tensile specimens were also cut from the semicircular sections (Figure 2c). Heat input into the specimens during the TIG welding process, was minimized by fabricating a clamping fixture. The fixture would allow alignment of the piece to the wire and was secured to the EDM table using a bolt. In order to investigate the effects of the pipe or reservoir curvature on the subsequent stress-strain data, flat, test specimens were also sectioned from mid wall of the same type pipe (Figure 3). The reservoir mock-ups used in this demonstration were not tritiumexposed. However, a similar machine could be purchased and used in the same facility with the proper radiological controls for cutting samples from tritium-exposed materials or components. 
Tensile samples were pulled to failure on a mechanical tensile machine. An example of the stress-strain data from one of the mock-ups is shown in Figure 4. The data can be used to establish baseline values of yield strength, ultimate strength, elongation, and ductility for samples taken from different sections. The stress-strain data will be used as material inputs to reservoir burst testing modeling efforts that are being conducted under a Plant Directed R\&D task. The stress-strain data have been shown to be similar to that collected from full-size tensile samples; however, values of elongation will have to be adjusted for the smaller gage length (Figure 5).

Tensile specimens were also sectioned from two T-Type reservoir mock-ups. One mock-up appeared to be fabricated from a forging because the wire was pinched several times during cutting apparently from relaxation of internal stresses. The other mock-up must have been fabricated from annealed bar stock because no movement of the part occurred during machining. This was later confirmed by tensile test data. The same technique developed for cutting the pipe was used for cutting the reservoir mock-ups. Fixturing was similar in shape but was scaled to fit the appropriate diameters. No attempt was used to minimize the re-melt region in these initial studies.

Samples of the longitudinal and transverse tensile specimens are shown in Figure 6 and 7. This work demonstrated that the EDM could be used to machine small tensile samples from the inside surface of the reservoir which would be most affected by tritium and decay helium.

A third K-Type mockup reservoir was sectioned using the wire EDM. The boss of this mockup was removed and sectioned such that five C-shaped fracture toughness samples could be fabricated (Figure 7 and 8). This fracture toughness sample has a rather complex shape; a print containing the dimensions of the sample is shown in Figure 9. Samples were cut from the mockup in two orientations to evaluate fracture toughness. In one sample the notch-tip at the crack mouth was machined on the inner diameter surface of the bore. This task demonstrated the accuracy of EDM (+/- 0.0005 in) and its ability to machine complex shapes from precise locations and maximizing the number of test samples fabricated. With careful cut planning and setup, test samples can be machined from any location and orientation in the reservoirs, including weldments, tritium-affected regions, and base metal.

\subsection{CONCLUSIONS}

The results of this investigation demonstrate that:

1) A variety of test samples can be machined from any location and orientation in a reservoir.

2) Tensile and fracture toughness samples can be machined from reservoir base metal, welds, heat-affected zones, and tritium affected regions near the surface.

3) Tensile properties measured were similar to those measured from full-size specimens. Minor corrections may be needed to account for the effects of specimen curvature and EDM recast layers. 


\subsection{RECOMMENDATIONS}

Future work should include following activities:

1) Investigate effect of recast layer on properties of EDM samples.

2) Compare fracture toughness properties of samples cut from a reservoir with historical fracture toughness measurements to samples cut from forward-extruded cylinders.

3) Purchase and install an EDM for fabricating samples from tritium-exposed reservoir components.

4) Use sub-size samples machined by EDM techniques to measure the properties of thin material sections.

5) Develop computer modeling tools for predicting reservoir performance from material property data.

\subsection{ACKNOWLEDGMENTS}

The authors would like to express their appreciation to Edward Majzlik for his support during the course of this work and to Kevin Kalbaugh and Glenn Chapman for operating the EDM and mechanical test systems. 


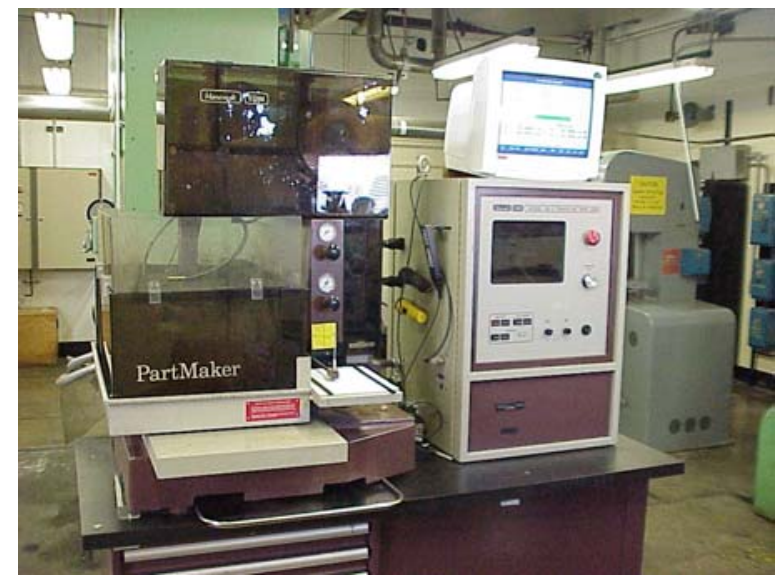

(a)

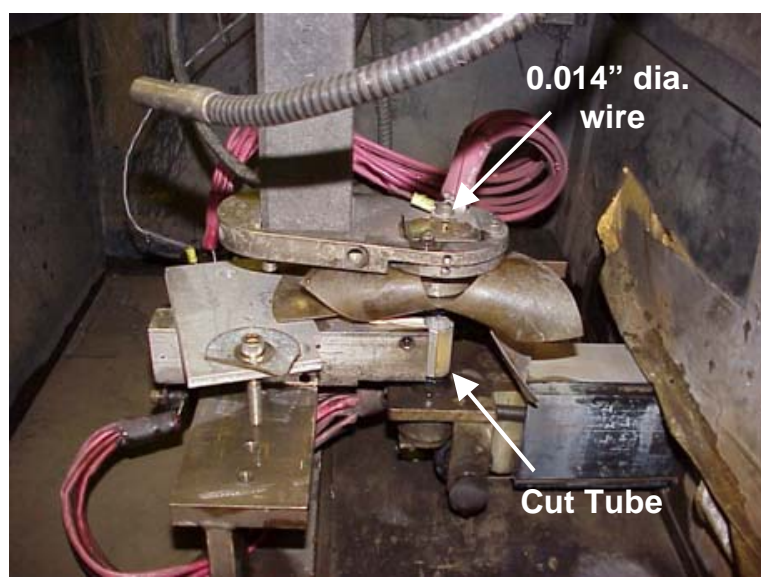

(b)

Figure 1. Hansvedt DS-2 PartMaker wire EDM a) EDM System and b) Arm showing part and 0.014 inch diameter wire.

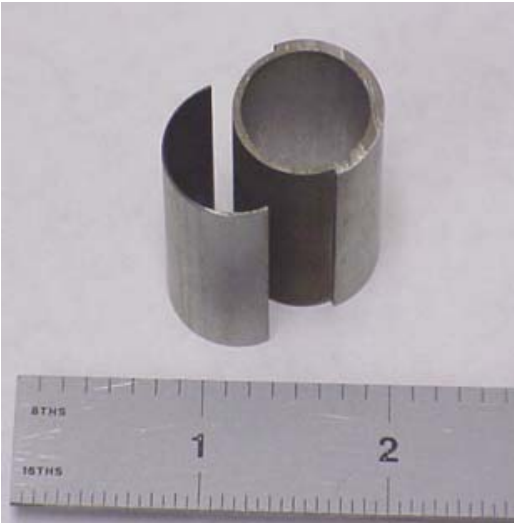

(a)

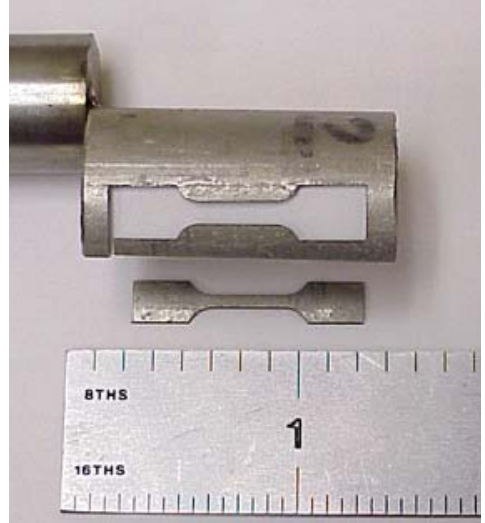

(b)

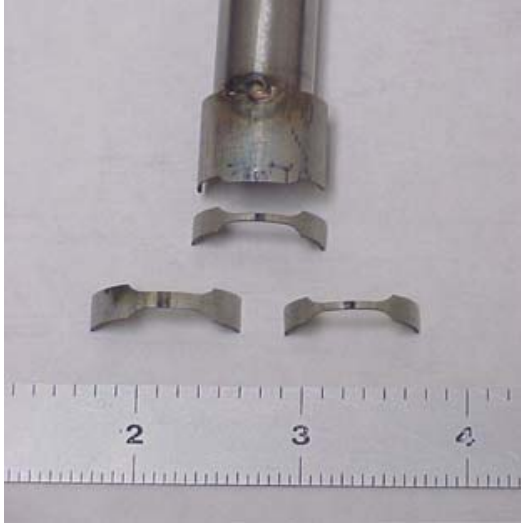

(c)

Figure 2. Photographs showing the wire EDM cuts necessary to section tensile specimens from 0.5 inch, sch. 10 pipe. a) Semicircular section 0.020 in thick sectioned from tube OD b) Miniature longitudinal tensile specimen c) Transverse tensile specimens.
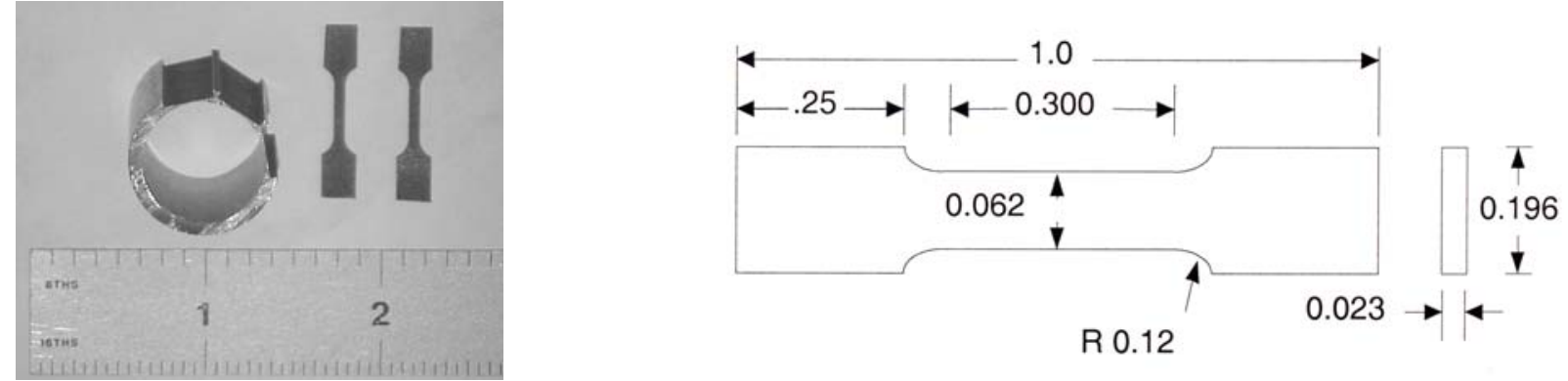

Figure 3. Rectangular tensile specimens cut from mid wall of the $1 / 2$ inch schedule 10 pipe and nominal dimensions. 


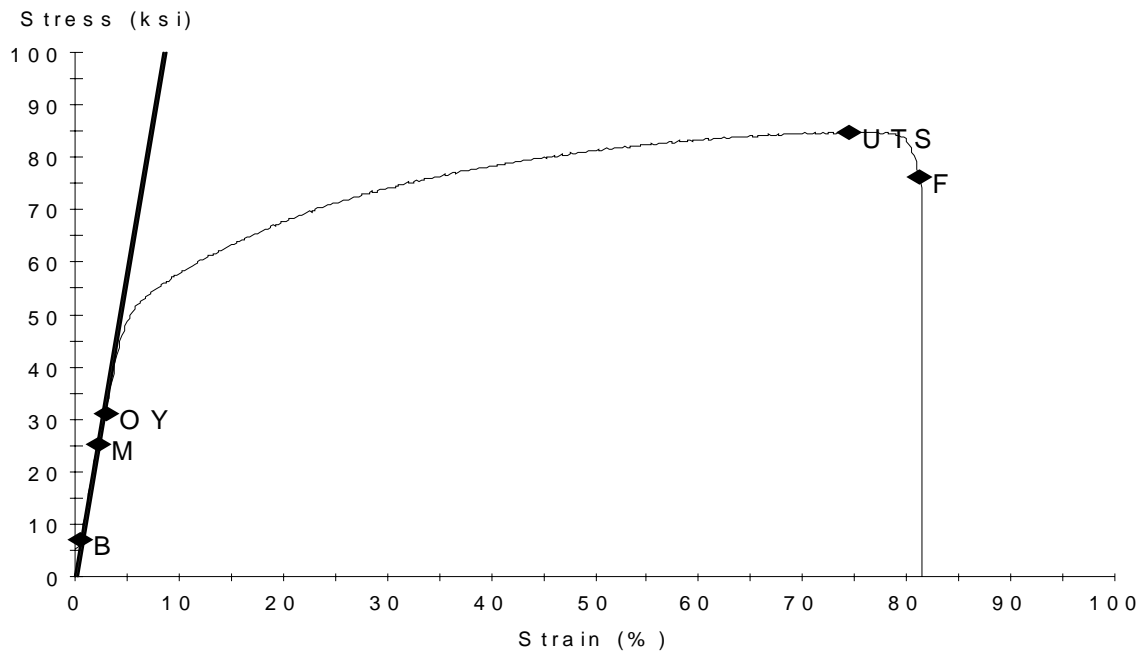

Figure 4. Typical stress strain data obtained from longitudinal EDM miniature tensile sample for T-Type reservoir.

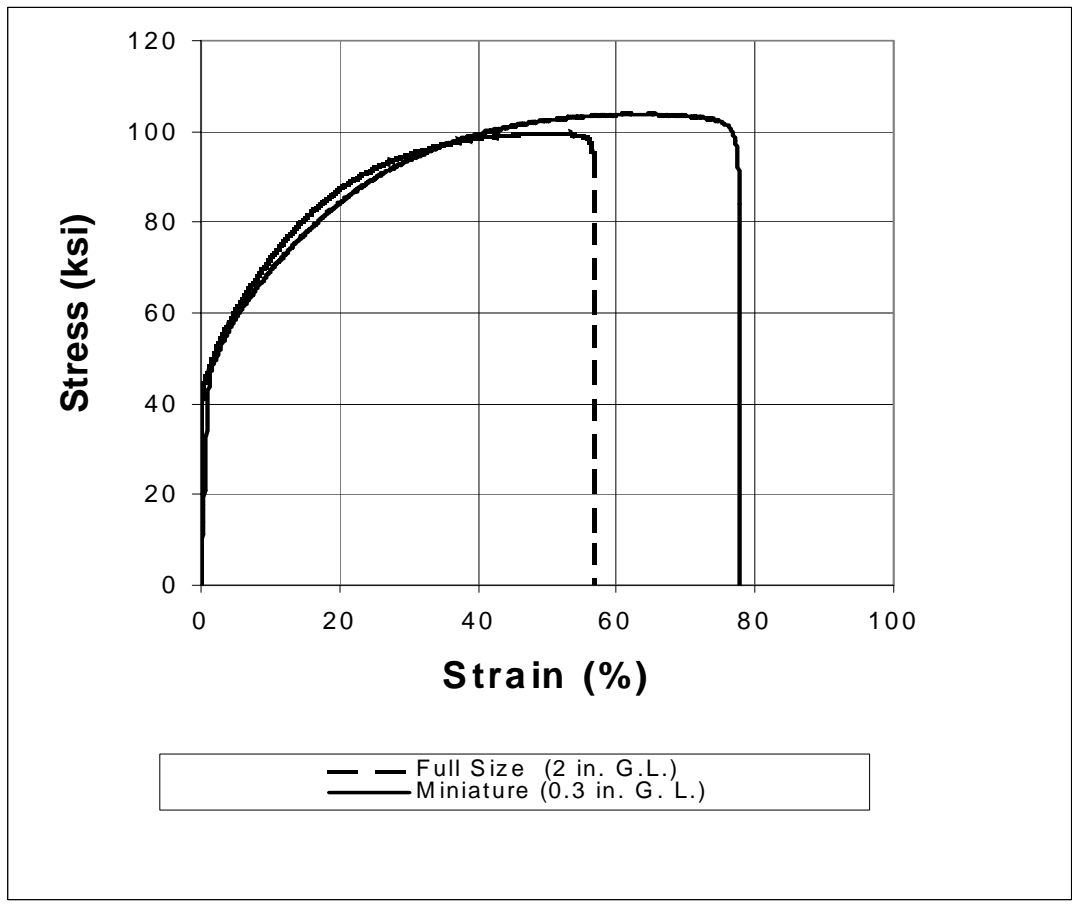

Figure 5. Stress strain diagrams for full-size and miniature tensile specimens. Stress strain data for both type samples are similar. Elongation of miniature sample is different because of gage length difference. 

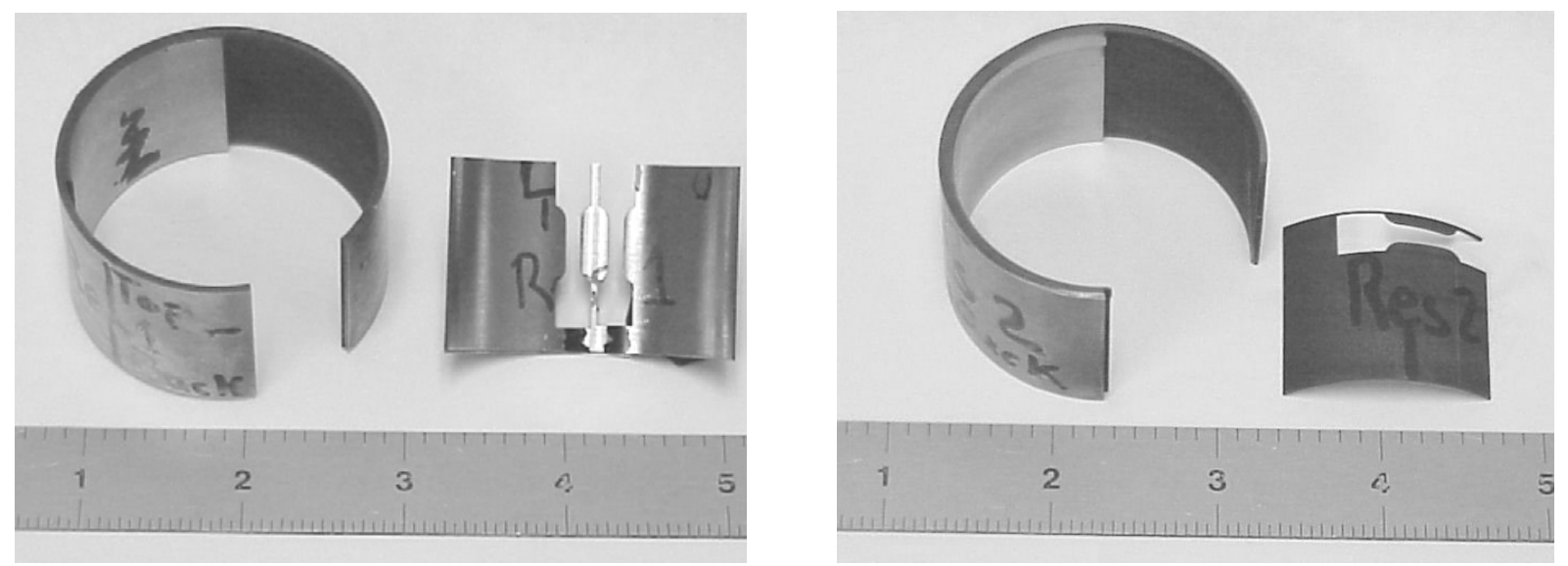

Figure 6. Large diameter mock-up reservoir showing locations where longitudinal and transverse tensile test coupons were sectioned from ID wall.
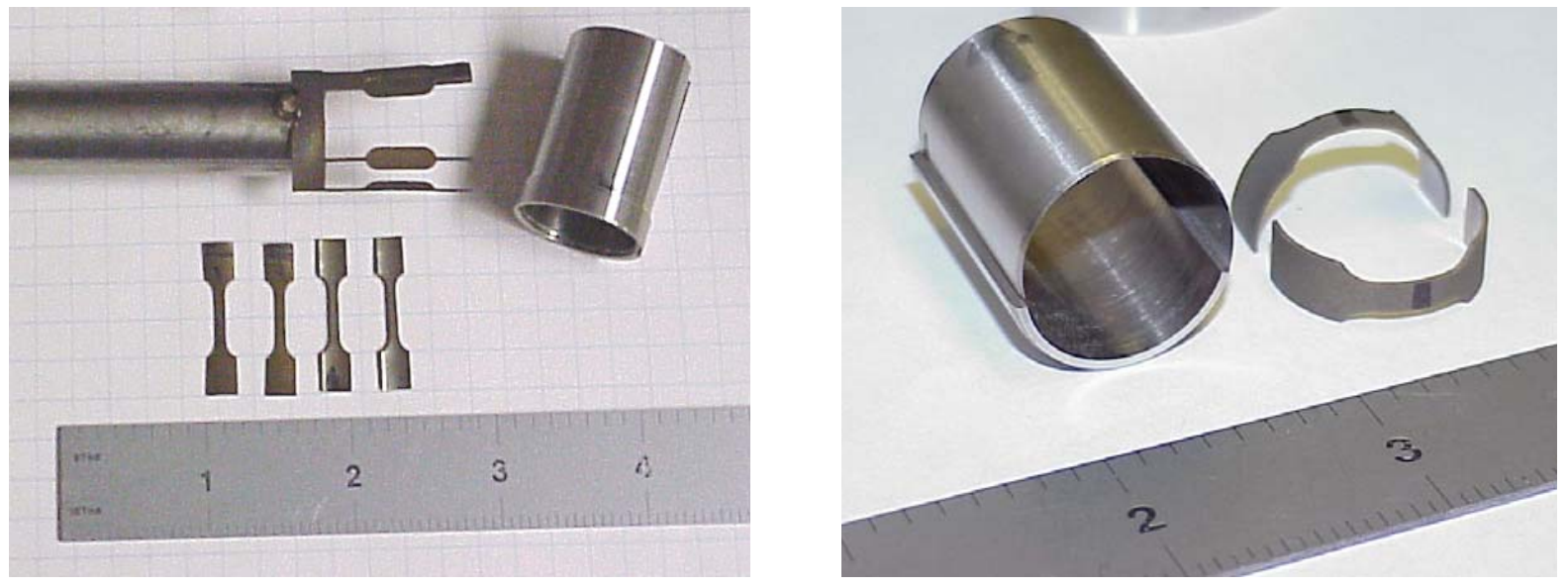

Figure 7. A small diameter mock-up reservoir showing locations where longitudinal and transverse tensile test coupons were sectioned from ID wall. 

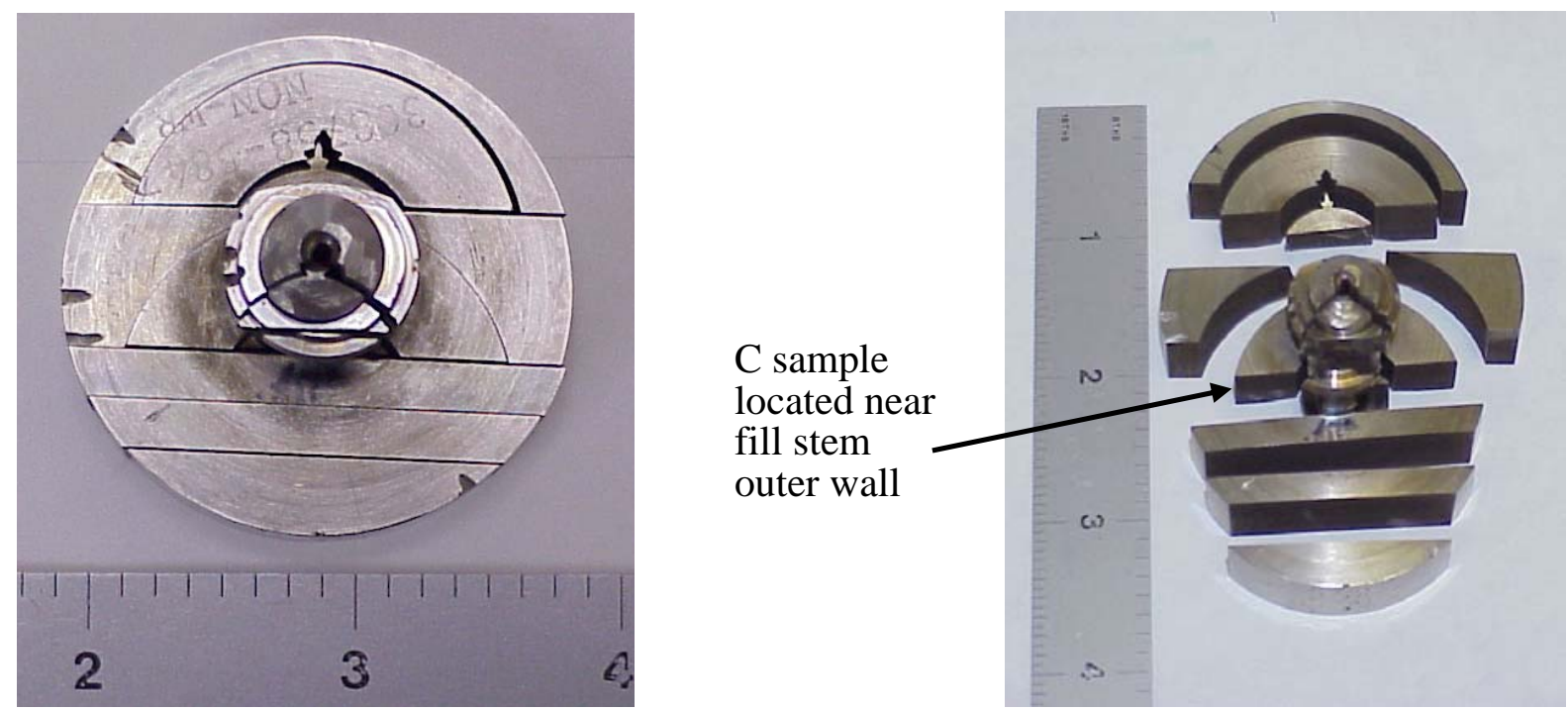

Figure 8. Boss from Type K reservoir mock-up after initial wire EDM process. Additional wire electrical discharge machining will be required to finish the fracture toughness samples.
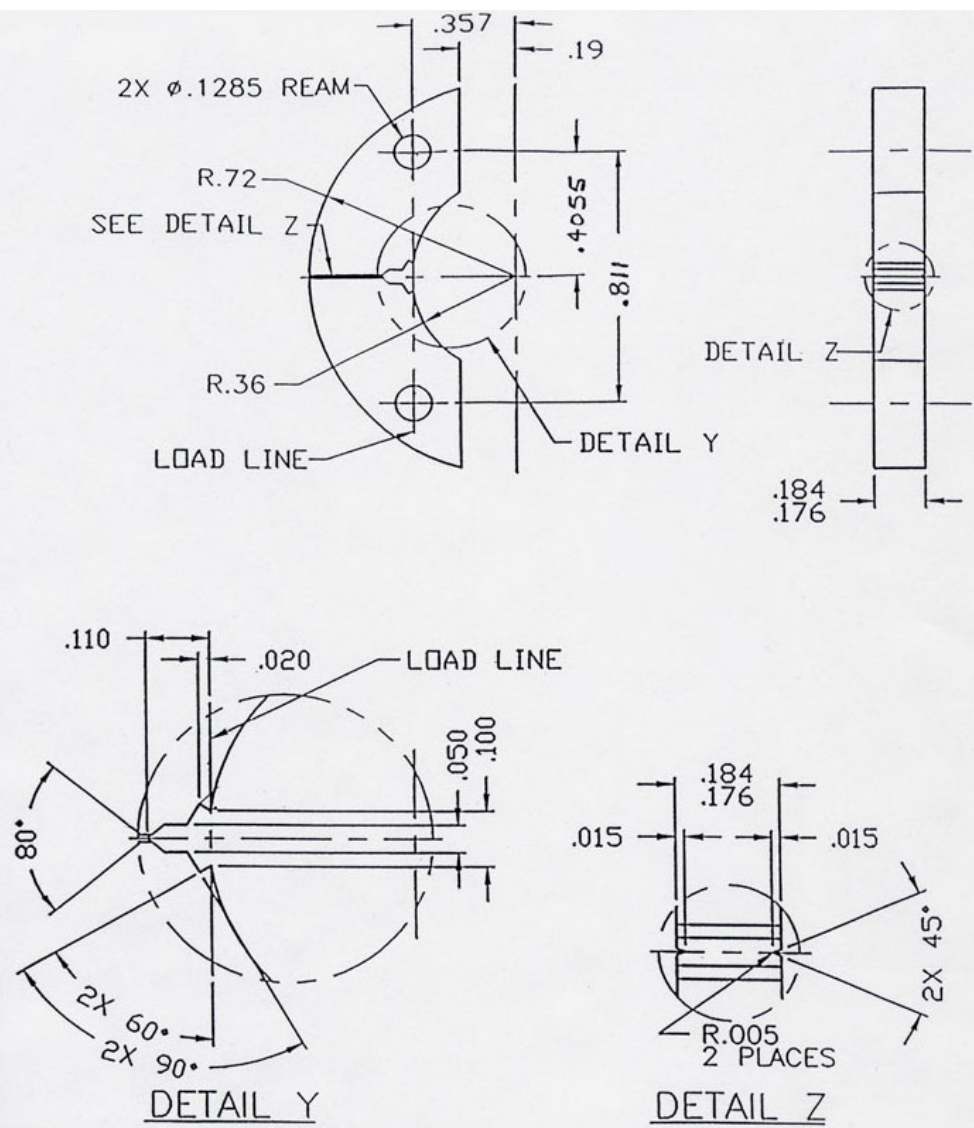

Figure 9. Drawing of the C sample including notch (detail Y) and side grooves (detail Z). 